\title{
BMJ Open International study of definitions of English-language terms for suicidal behaviours: a survey exploring preferred terminology
}

Diego De Leo, ${ }^{1}$ Benjamin Goodfellow (D) , ${ }^{1,2}$ Morton Silverman, ${ }^{3}$ Alan Berman, ${ }^{4}$ John Mann, ${ }^{5}$ Ella Arensman, ${ }^{6}$ Keith Hawton (D) ,7 M R Phillips, ${ }^{8,9}$ Lakshmi Vijayakumar, ${ }^{10}$ Karl Andriessen (D) , ${ }^{11}$ Ana-Maria Chavez-Hernandez, ${ }^{12}$ Marnin Heisel, ${ }^{13,14}$ Kairi Kolves (D) ${ }^{1}$

To cite: De Leo D, Goodfellow B, Silverman M, et al. International study of definitions of English-language terms for suicidal behaviours: a survey exploring preferred terminology. BMJ Open 2021;11:e043409. doi:10.1136/ bmjopen-2020-043409

- Prepublication history and additional materials for this paper is available online. To view these files, please visit the journal online (http://dx.doi. org/10.1136/bmjopen-2020043409).

Received 02 August 2020 Revised 27 January 2021 Accepted 28 January 2021
Check for updates

(C) Author(s) (or their employer(s)) 2021. Re-use permitted under CC BY-NC. No commercial re-use. See rights and permissions. Published by BMJ.

For numbered affiliations see end of article.

Correspondence to Professor Diego De Leo; d.deleo@griffith.edu.au

\section{ABSTRACT}

Objectives Explore international consensus on nomenclatures of suicidal behaviours and analyse differences in terminology between high-income countries (HICs) and low/middle-income countries (LMICs). Design An online survey of members of the International Organisation for Suicide Prevention (IASP) used multiple-choice questions and vignettes to assess the four dimensions of the definition of suicidal behaviour: outcome, intent, knowledge and agency.

Setting International.

Participants Respondents included 126 individuals, 37 from 30 LMICs and 89 from 33 HICs. They included 40 IASP national representatives (65\% response rate), IASP regular members (20\% response rate) and six respondents from six additional countries identified by other organisations.

Outcome measures Definitions of English-language terms for suicidal behaviours.

Results The recommended definition of 'suicide' describes a fatal act initiated and carried out by the actors themselves. The definition of 'suicide attempt' was restricted to non-fatal acts with intent to die, whereas definition of 'self-harm' more broadly referred to acts with varying motives, including the wish to die. Almost all respondents agreed about the definitions of 'suicidal ideation', 'death wishes' and 'suicide plan'. 'Aborted suicide attempt' and 'interrupted suicide attempt' were not considered components of 'preparatory suicidal behaviour'. There were several differences between representatives from HICs and LMICs.

Conclusion This international opinion survey provided the basis for developing a transcultural nomenclature of suicidal behaviour. Future developments of this nomenclature should be tested in larger samples of professionals, including LMICs may be a challenge.

\section{INTRODUCTION}

An important limitation to the generalisation of suicide research outcomes is the absence of international consensus on terminologies and definitions, making it difficult to
Strengths and limitations of this study

- The strength of the study is the inclusion of a range of countries and professional backgrounds.

- The main limitations are the relatively low participation rate and restriction to the English language.

- There was a differential representation from highincome countries and low/middle-income countries.

compare interpretations and categories of suicidal behaviour among studies originating in different parts of the world. Attempts at developing a nomenclature for suicidal behaviours (eg, see references ${ }^{1-3}$ ) have not reached international consensus. ${ }^{4}$ Several classifications of suicidal behaviours have also been developed and some were based on the noted nomenclatures. ${ }^{5}$ To date, the only classification validated by the WHO is a classification restricted to methods of self-harm. ${ }^{6}$ To our knowledge, there are no previous surveys focussing on reaching consensus on a nomenclature of suicidal behaviours. Therefore, the International Association for Suicide Prevention (IASP) has constituted a Special Interest Group for the development of an internationally applicable nomenclature of suicidal behaviours. $^{7}$

According to official mortality statistics, 793000 people worldwide died by suicide in $2016 ; 79 \%$ of these cases were from low/ middle-income countries (LMIC), ${ }^{8}$ while most research outputs on suicidal behaviour are produced in high-income countries (HIC). Furthermore, most definitions and terms of common use originate from HIC. ${ }^{9}$ However, since LMICs are increasingly producing research on suicide and its prevention, it would be important to obtain a clearer 
picture of the definitions and terms used around the world.

This article presents the results of the International Study of Definitions of English-Language Terms for Suicidal Behaviors (ISDELTSB), which aimed to assemble a minimum set of commonly understood and widely used terms and definitions to describe suicidal phenomena. ${ }^{10}$ Furthermore, we explore differences in preferred terminologies between HICs and LMICs.

\section{METHODOLOGY}

The ISDELTSB methodology was based on a survey of members of international organisations having interest in the study and prevention of suicide, namely the IASP, the World Psychiatric Association (WPA) and the World Organization of National Colleges, Academies and Academic Associations of General Practitioners/Family Physicians' (WONCA), with an effort to recruit from the widest possible range of countries. An initial sample was built with one representative per country. ${ }^{10}$ These individuals were expected to provide answers that were representative of the views of professionals working in their country. However, the initial call to national delegates of IASP and members of the other associations resulted in a small number of responses. It was therefore decided to widen the study sample by inviting all IASP members to participate, assuming that their interest in suicide prevention could be paralleled by a degree of knowledge in the field of suicide higher than that of lay people. Consequently, each participating country had either one 'expert' (ie, an IASP national representative, or a member of WPA or WONCA), or at least one IASP member.

The survey questionnaire proposed a variety of terms and definitions commonly found in the literature. Details about the questionnaire and other details about methodology are presented in an open access journal. ${ }^{10}$

\section{Sample characteristics}

Data were collected in 2018. Initially, as said, respondents comprised only IASP national representatives; among the 62 existing national delegates of the association, 40 agreed to join the study. Three more countries were identified-respectively—by two people designated by the WPA and one by the WONCA. Another three participants were eventually identified by the staff of Australian Institute for Suicide Research and Prevention's among those countries with no IASP delegate. In this way, representatives from 46 countries took part to the study. To further increase the number of participants, invitation to join the study was extended to all members of IASP. Out of 408 IASP regular members (excluding national delegates), 80 agreed to take part in the study. The final number of consenting respondents was 126 from 63 countries or territories, 37 from 30 LMICs and 89 from 33 HICs. The list and the map of participating countries are available in online supplemental table 1 and figure 1.
English language was an official language or one of the official languages in 23 out of 63 countries; 61 respondents were from a country in which English was not an official language and 65 were from a country where it was not. Concerning professional background of participants, $30 \%$ were medical doctors, $29 \%$ were psychologists, $10 \%$ were epidemiologists and $31 \%$ were from 'other' professions (eg, social worker, student, sociologist, public health professional, teacher, etc).

\section{Patient and public involvement}

No patients involved.

\section{Statistical analyses}

Statistical analyses were performed using IBM SPSS V.25.0. Our focus was on the most frequently used terms. Analyses computed ORs with $95 \%$ CIs to compare HICs versus LMICs. There were limited missing data $(0 \%-6.3 \%)$, which were left out from the analyses of specific items. To enable country-based analyses, we conducted sensitivity analyses by calculating weights for countries where there were more than one respondent, which also allowed a more even comparison between HICs and LMICs.

\section{RESULTS \\ Definition of suicide}

Agreement on the definition of suicide was assessed by providing a set of statements for each of the main components of the definition: outcome, intent, knowledge and agency. ${ }^{4}$ Respondents had to choose the suggestion with which they agreed. The choices of respondents by LMICs versus HICs are shown in figure 1.

Majority $(81.6 \%$; 1 missing) agreed that, 'Suicide is an act that necessarily leads to death'. Regarding intent, five non-mutually exclusive statements were proposed (figure 1). More than half of respondents agreed with the last statement (5: 'Suicide is an act that may be done without explicit intent to die'). However, respondents agreed more frequently with statements 2-4 (2: 'Suicide is an act that may be done with an intent other than an explicit intent to die'; 3: 'Suicide is an act that may be done with an ambiguous or unclear intent'; 4: 'Suicide is an act that may be done with an intent to take the risk of dying'). Respondents from HIC were more likely to choose statement 3 (OR: 2.35; 95\% CI 1.03 to 5.36), but also in the LMIC group almost $60 \%$ of respondents agreed with this statement.

In terms of knowledge of the consequences of the act, four statements were proposed. More than half the respondents agreed with the statement: 'Suicide is an act that can be performed with the knowledge of a fatal result, but the person is not certain of that result', regardless of national income. Regarding agency, more than half $(60 \% ; 1$ missing) of respondents agreed with the statement, 'Suicide is an act that is initiated by oneself, but not necessarily carried out by oneself to the end of the action'. 

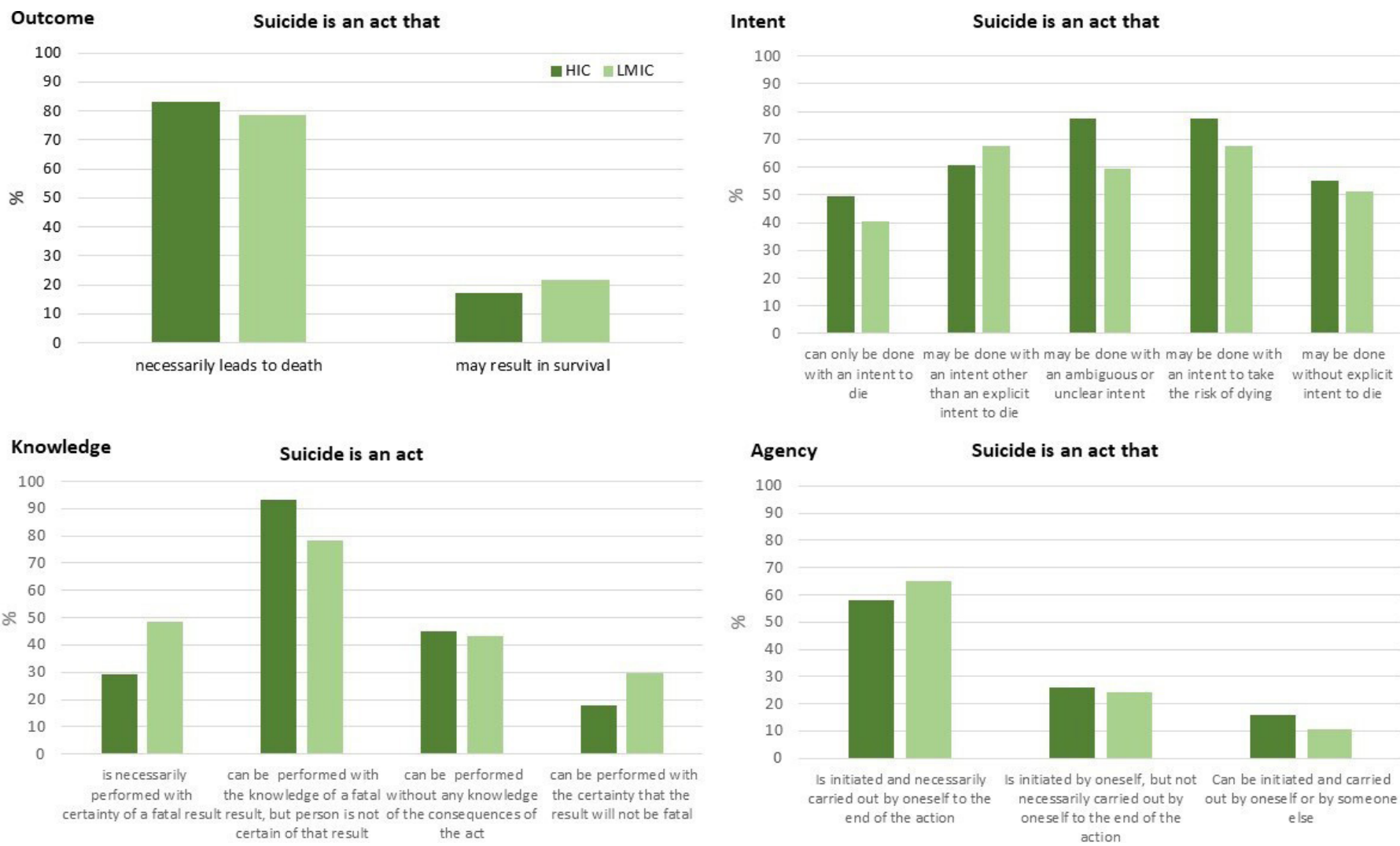

Figure 1 Percentage of respondents who agreed with statements regarding the definition of suicide according to national income in the International Study of Definitions of English-Language Terms for Suicidal Behaviors sample. HIC, high- income country; LMIC, low/middle-income country.

\section{Definition of non-fatal forms of suicidal behaviours}

For non-fatal suicidal behaviours, a vignette method was used and a set of 16 basic clinical scenarios was proposed. For each vignette, a list of terms was proposed from which respondents had to choose a single answer. The percentages of agreement with particular terms for vignettes 1-16 according to respondents' countries' national income are presented in figures 2 and 3.

Vignette 1 asked respondents how they would name the act of a person who harmed himself or herself with the intention to die but survived. The majority of respondents $(92.1 \%)$ named the act as a 'suicide attempt' (figure 2). Vignette 2 described a person who harmed himself or herself without any intention to die and survived. The answers were not unanimous; however, the highest agreement was reached for the term 'self-harm' (27.8\%), followed by 'non-suicidal self-injury' (19\%) and 'deliberate self-harm' (17.5\%). Vignette 3 described a person who harmed himself or herself without any intention to die but died. The highest level of agreement was reached for 'suicide' (24.0\%), although 'accident' was also a frequent choice $(17.6 \%)$.

Vignette 4 asked respondents to define the act of a person who harmed himself or herself, but, for whatever reasons, could not state his or her intentions and the person survived. While a 'suicide attempt' was the most frequent choice for LMIC $(37.8 \%)$, HICs chose 'selfharm' most frequently (21.8\%; OR: $0.40 ; 95 \%$ CI 0.17 to $0.93 ; 2$ missing). Vignette 5 described a person who harmed himself or herself but did not want to state his or her intentions and the person survived. The closest levels of agreement between income groups were for 'suicide attempt' (27.4\%) even though the HIC group chose 'selfharm' most frequently (26.4\%).

Vignette 6 asked respondents to define the act of a person who died as a consequence of harming himself or herself, but his or her intentions in doing so could not be known or inferred. Two answers stood out: 'suicide' (42.1\%) and 'undetermined death' (31.7\%). Respondents from HICs were more likely to choose 'undetermined death' (HICs: $37.1 \%$ vs LMICs: $18.9 \%$; OR: 2.53; $95 \%$ CI 1.00 to 6.39 ), and respondents from LMICs 'suicide' (HICs: $37.1 \%$ vs LMICs: $54.1 \%$; OR: 0.50; CI $95 \% 0.23$ to 1.09$)$.

Vignette 7 described someone who occasionally thought of suicide when feeling distressed: all groups chose 'suicidal ideation' most frequently (64.8\%). Vignette 8 described someone who continuously thought of suicide but had no suicidal intent. All groups chose 'suicidal ideation' most frequently $(45.2 \%)$, followed by 'persistent suicidal ideation' (31\%).

Figure 3 shows respondents' answers to vignettes $9-16$ according to income level. Vignette 9 described someone who hoped for death but had no thoughts of killing himself or herself. Respondents chose 'death wishes' $(57.6 \%)$ most frequently across all groups. Vignette 
Vignette 1 (...) when a person harms him-or herself, with the intention to die, and survives, his or her act is

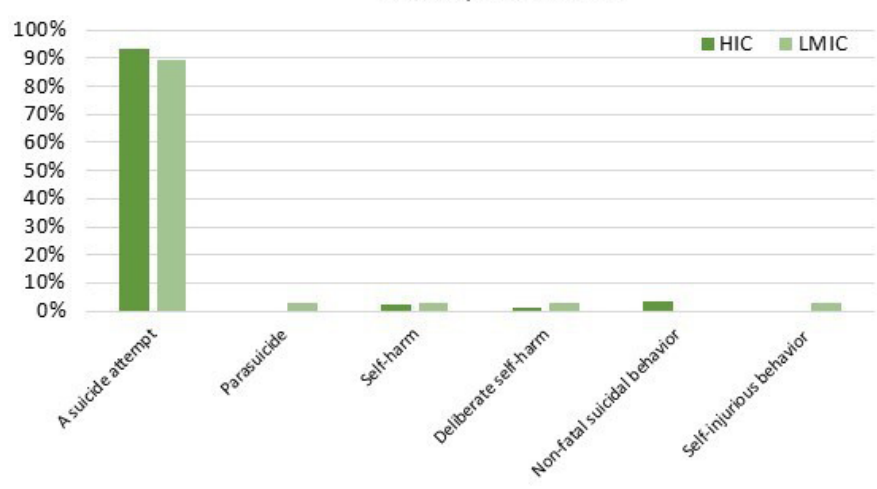

Vignette 3 (...) when a person harms him-or herself without any intention to die, and dies, his or her act is

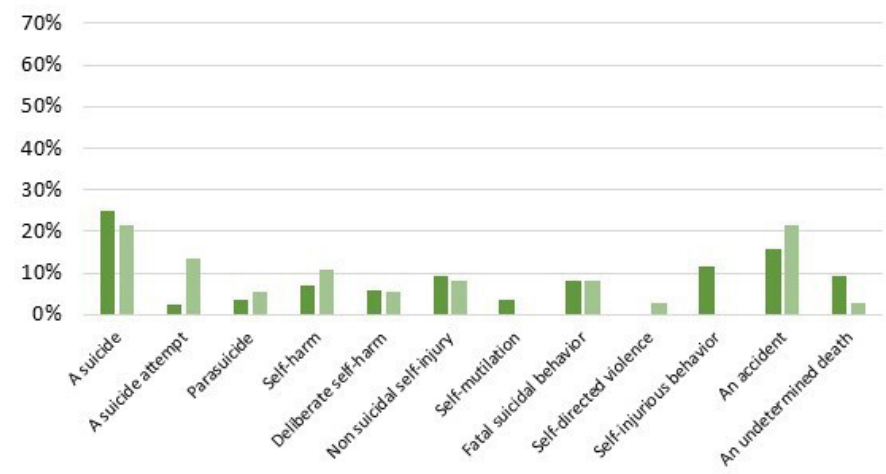

Vignette 5 (...) when a person harms him-or herself, but does not want to state his

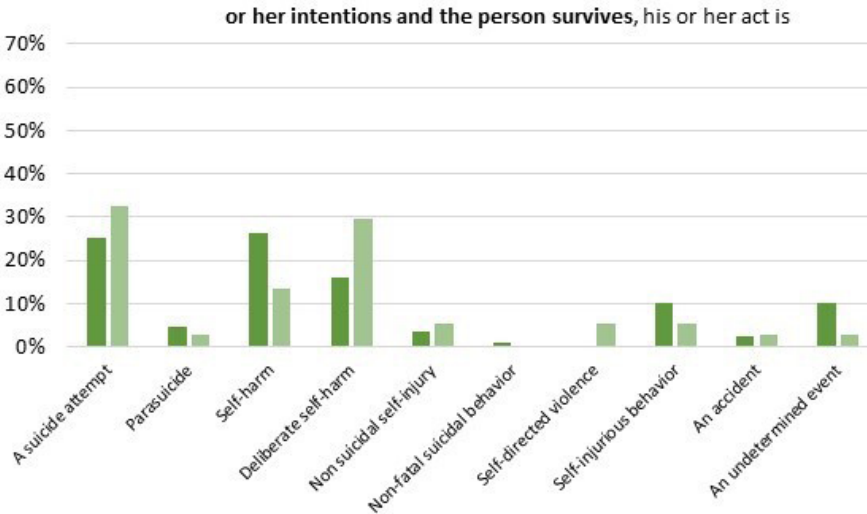

Vignette 7 (...) when someone who occasionally thinks of suicide when confronted to distress, this person has

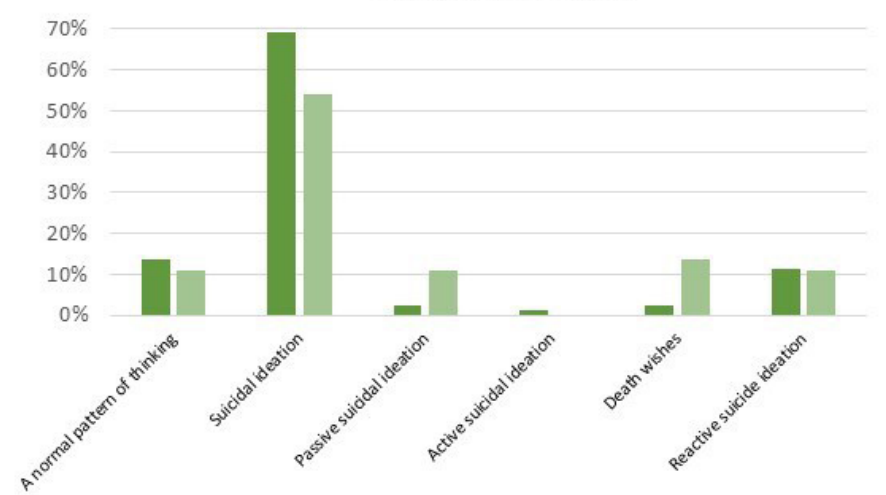

Vignette 2 (...) when a person harms him- or herself without any intention to die, and survives, his or her act is

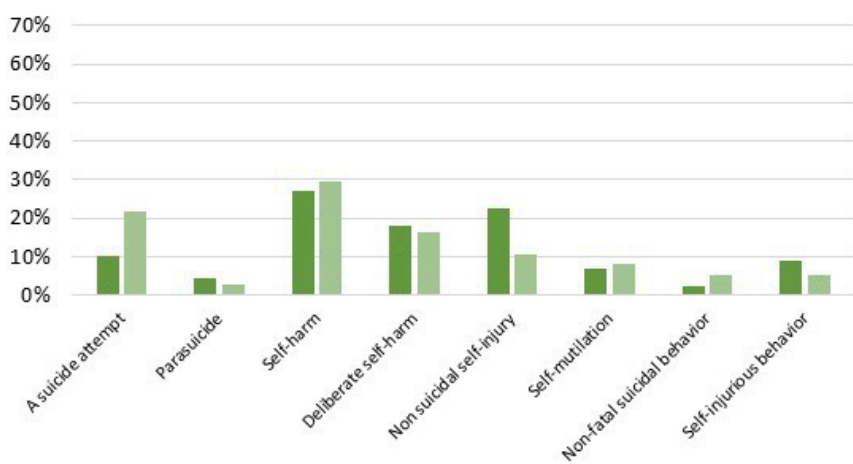

Vignette $\mathbf{4}(. .$.$) when a person harms him- or herself, but, for whatever reasons, cannot$ state his or her intentions and the person survives, his or her act is

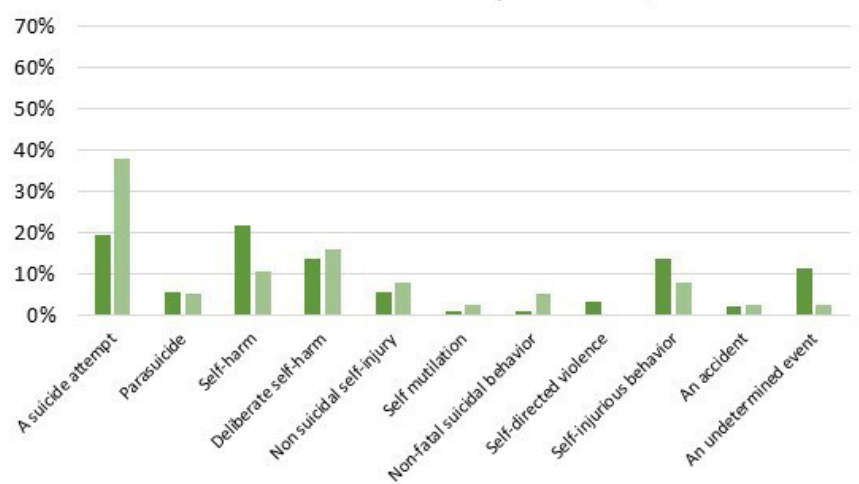

Vignette 6 (...) when a person dies as a consequence of harming him or herself, but his or her intentions in doing so cannot be known or inferred, his or her act is

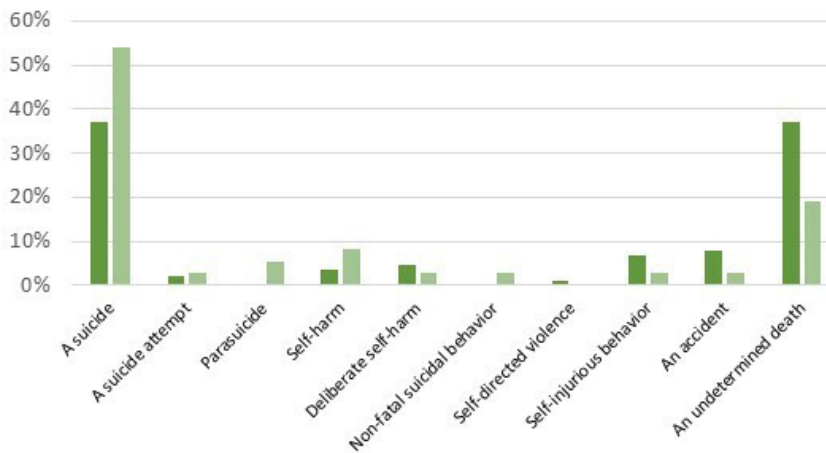

Vignette 8 (...) when someone who continuously thinks of suicide but has no suicidal intent, this person has

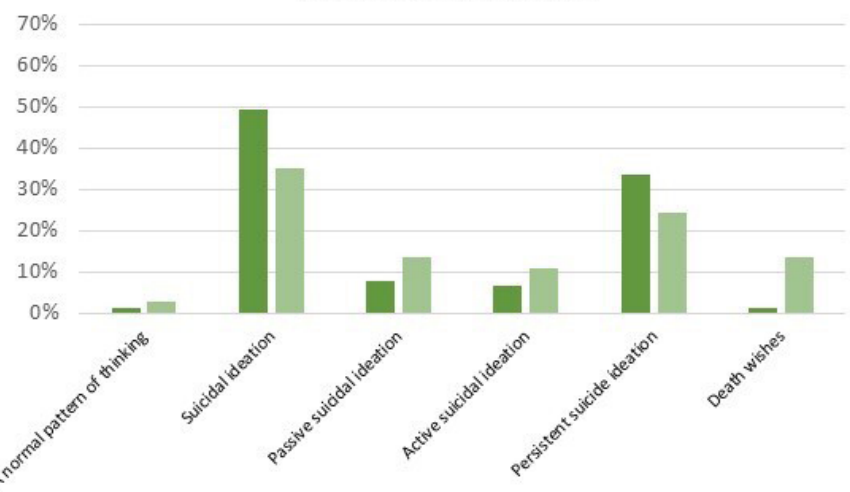

Figure 2 Percentage of respondents agreeing to statements regarding the definition of suicidal behaviours (vignettes 1-8) by national income in International Study of Definitions of English-Language Terms for Suicidal Behaviors sample HIC, highincome country; LMIC, low/middle-income country. 
Vignette 9 (...) when someone who hopes for death but has no thoughts of killing Vignette 10 (...) when someone hopes for death by killing him- or herself, this him- or herself, this person has person has

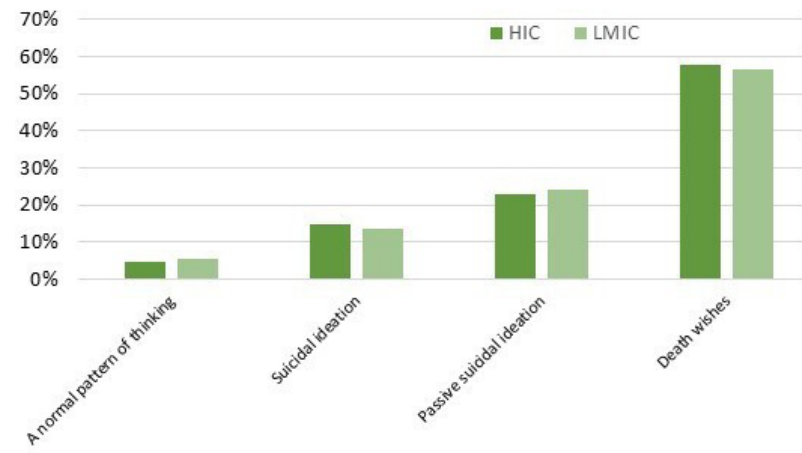

Vignette 11 (...) when someone states suicidal intention without engaging in behavior, this person

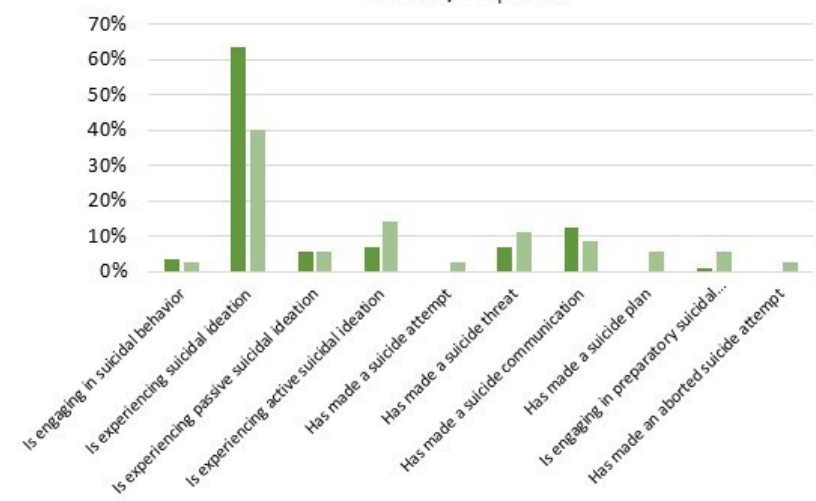

Vignette 13 (...) when someone has decided how and when to perform a suicidal act, but does not actively prepare anything, this person

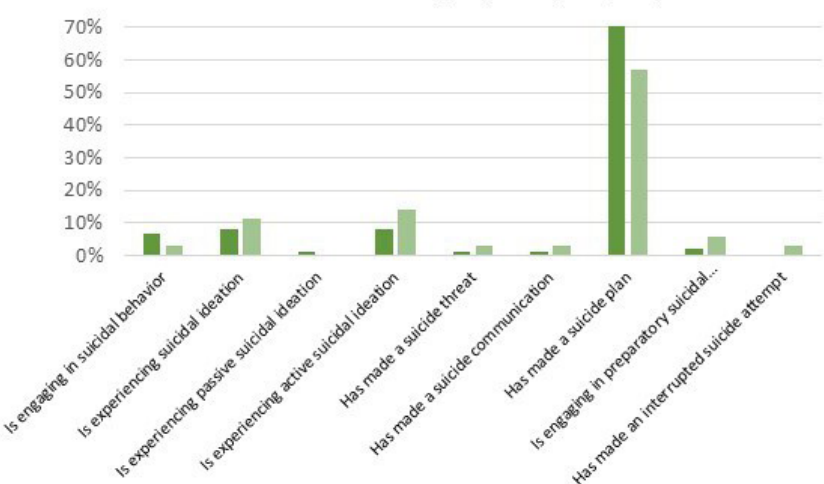

Vignette 15 (...) when someone initiates a suicidal act (e.g. stands or sits on the edge of a high bridge, ties a rope around his or her neck), but stops him or herself before sustaining any injuries, this person
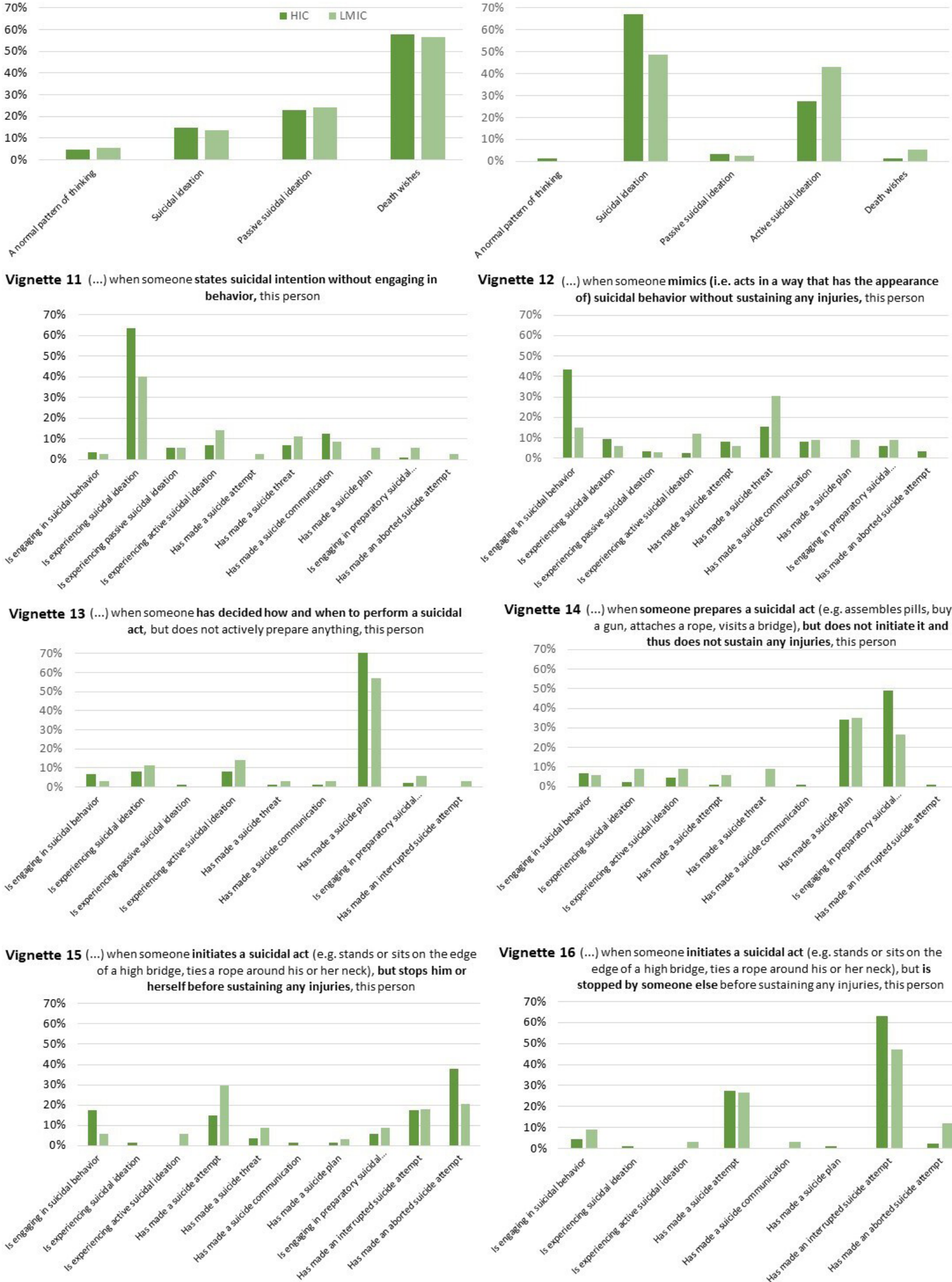

Vignette 12 (...) when someone mimics (i.e. acts in a way that has the appearance of) suicidal behavior without sustaining any injuries, this person

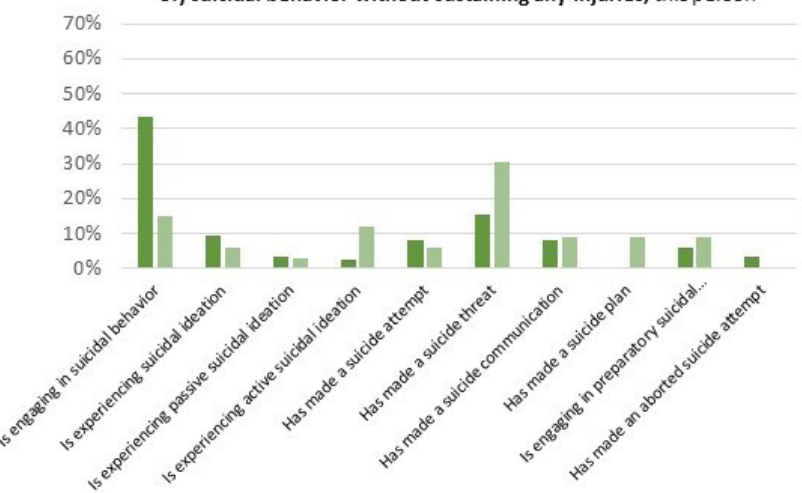

Vignette 14 (...) when someone prepares a suicidal act (e.g. assembles pills, buys gun, attaches a rope, visits a bridge), but does not initiate it and
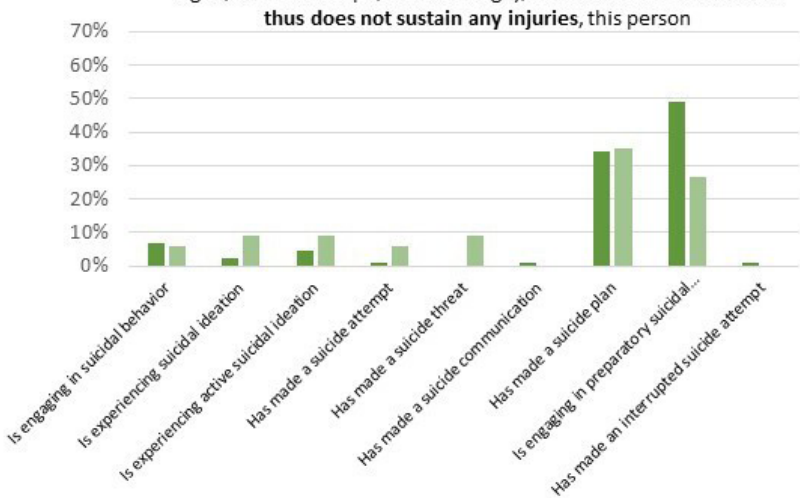

Vignette 16 (...) when someone initiates a suicidal act (e.g. stands or sits on the edge of a high bridge, ties a rope around his or her neck), but is stopped by someone else before sustaining any injuries, this person

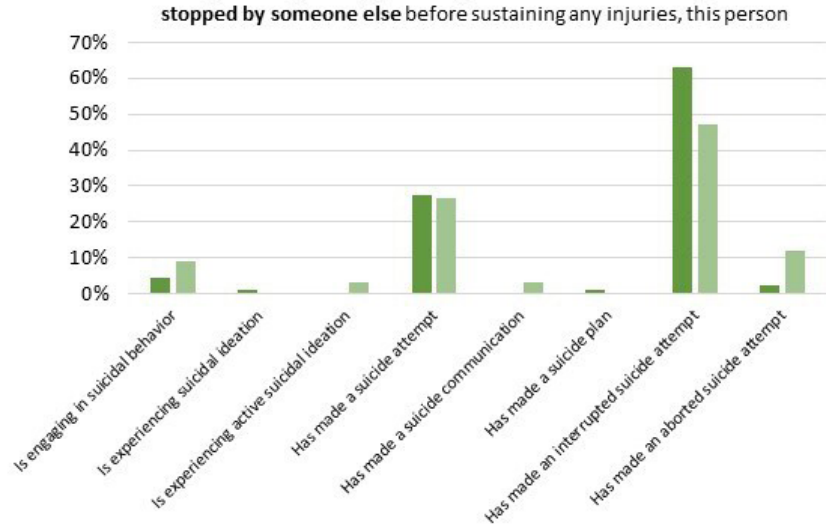

Figure 3 Percentage of respondents agreeing to statements regarding the definition of suicidal behaviours (vignettes 9-16) by national income in International Study of Definitions of English-Language Terms for Suicidal Behaviors sample. HIC, highincome country; LMIC, low/middle-income country. 
10 described someone who hoped for death by killing himself or herself, and most respondents chose the 'suicidal ideation' (61.6\%) followed by 'active suicidal ideation' (32\%).

The following vignettes described behaviours that could be considered as being at the boundary between behaviour and ideation and could therefore be subject to debate. Vignette 11 asked respondents to choose a term for someone who stated suicidal intention without engaging in the behaviour. Although all groups most frequently decided that the person was experiencing 'suicidal ideation' (56.9\% for all), HICs' respondents were more likely to choose 'suicidal ideation' than LMICs (HICs: $63.6 \%$, LMICs: 40\%; OR: 2.63; 95\% CI 1.18 to 5.87; 3 missing).

Vignette 12 described someone who mimicked (ie, acted in a way that had the appearance of) suicidal behaviour without sustaining any injuries. The two most frequently chosen answers were 'suicidal behaviour' $(35.6 \%)$ and 'suicide threat' $(19.5 \%)$. However, HICs' respondents were more likely to choose 'suicidal behaviour' (HICs: 63.6\% vs LMICs: $40 \%$; OR: 4.32; 95\% CI 1.52 to 12.26 ; 8 missing). Vignette 13 asked the respondent to define the behaviour of someone who had decided how and when to perform a suicidal act, but did not actively prepare anything. The 'suicide plan' was most commonly chosen (67.5\%). Vignette 14 described someone who prepared a suicidal act (eg, assembled pills, bought a gun, attached a rope, visited a bridge), but did not initiate it and consequently did not sustain any injuries. The two most frequently chosen options were 'preparatory suicidal behaviour' (42.6\%) and 'suicide plan' (34.4\%). HICs' respondents were more likely to choose 'preparatory suicidal behaviour' (HICs: $48.9 \%$ vs LMICs: $26.5 \%$; OR: $2.65 ; 95 \%$ CI 1.11 to $6.33 ; 4$ missing) and the LMIC group chose 'suicide plan' most frequently (HICs: $34.1 \%$ vs LMICs: $35.3 \%$ ).

Vignette 15 asked the respondent to define the behaviour of someone who initiated a suicidal act (eg, stood or sat on the edge of a high bridge, tied a rope around his or her neck), but stopped himself or herself before sustaining any injury. The 'aborted suicide attempt' was the most commonly chosen option $(33.1 \%)$ followed by the 'suicide attempt' (19\%). The HIC group chose the 'aborted suicide attempt' most frequently (HICs: $37.9 \%$ vs LMICs: 20.6\%; OR: 2.65 ; $95 \%$ CI 1.11 to 6.33 ; 5 missing) whereas the LMIC group chose 'suicide attempt' (HICs: 14.9\% vs LMICs: $29.4 \%$; OR: 2.36 ; $95 \%$ CI 0.92 to $6.02 ; 5$ missing). Vignette 16 described someone who initiated a suicidal act (eg, stood or sat on the edge of a high bridge, tied a rope around his or her neck), but was stopped by someone else before sustaining any injuries. The majority agreed on the 'interrupted suicide attempt' (58.7\%), followed by the 'suicide attempt' (27.3\%).

\section{Sensitivity analyses}

Changing the level of analysis from individual respondents to responses by country yielded no differences in in the most commonly chosen item; in general, the change remained within $\pm 10 \%$ (ST 2 and 3 ). Comparisons between HICs and LMICs showed some changes in the order. For vignettes 5 and 6 , the most frequently chosen item by HICs changed into the same as in LMICs and for vignettes 3 and 14, the LMICs most predominant item became more similar to HICs (SF 2-4).

\section{DISCUSSION}

To our knowledge, the ISDELTSB is the first empirical study aiming to assemble a minimum set of consensus based and widely used terms and definitions to describe suicidal phenomena. The results of the present study could give a contribution in this direction, while also looking at differences between HICs and LMICs regarding terminologies used. The answers of survey participants regarding the four characteristics of the definition of suicide could delineate some level of consensus. Regarding outcome, all respondents agreed that suicide is an act resulting in death. This sets a clear distinction between suicide and non-fatal suicidal behaviours and corresponds to the majority of definitions of suicide found in the literature. ${ }^{10}$

Regarding intent, more than half of respondents agreed that suicide could be undertaken without explicit intent to die, despite the fact that, only a few definitions of suicide do not mention intent to die as a central characteristic of the act. ${ }^{111}{ }^{12}$ In De Leo et al ${ }^{13}{ }^{13}$ definition, intent targeted 'wanted changes' (p12). These authors argued that intent to die-assumed to be at least in minimal part present (ie, greater than zero)—can be concurrent with other purposes, and that people attempting suicide may even be trying to improve their life or have other underlying motives, such as escaping from an unbearable situation. According to the answers to our survey, suicide is an act in which intent may not be explicit but ambiguous and unclear, and involving the risk of dying.

In the literature, knowledge of potentially fatal outcome was often suggested as a requirement for the definition of suicide. ${ }^{913}$ In the present survey, according to the vast majority of respondents, suicide is an act carried out with the knowledge of a potentially fatal result.

The respondents stressed the importance of distinguishing suicide from assisted suicide and euthanasia. Generally, they expressed the choice for a definition excluding the possibility of an outside agent. This appears in contradiction with most literature (eg, Goodfellow et $\left.a \ell^{\natural}\right)$. According to most respondents in this study, suicide is an act initiated and carried out by oneself to the end of the action. However, in our view, if widely accepted, this determination could lead to several problems, contributing to a substantial underestimation of suicide mortality. For instance, an act in which a person stands in front of a moving object (eg, a train or a truck driven by another person) could hardly be considered as assisted suicide. Keeping in mind the limitations of the present survey (eg, representativeness of the sample; clarity of vignettes; deepening of details, etc), the indications coming from 
this area of our study seem to emphasise the importance of a shared set of definitions among scholars in the field of suicide. The discrepancy detected at the level of definition of suicide among study participants is of relevance and underlines the appropriateness of research efforts in the definitional domain. Indeed, if we identify what varies and explain why, we should equally succeed in identifying what does not, that is, shared terms and definitions. Further research should thus use the same methodology and focus on a wider sample of professionals working in the field.

Evidence of intent to die is central to the definition of 'suicide attempt', a behaviour in which a person harms himself or herself, with the intention to die, and survives, and is in agreement with the existing literature. ${ }^{1214}$ The term 'suicide attempt' was deemed acceptable in a wide scale survey and recommended for academic and media use. ${ }^{15}$ 'Self-harm' was the preferred term in cases in which there was no evidence of intent to die (ie, vignette 2) and elicited less disagreement than 'suicide attempt' when intent could not be determined (ie, vignettes 4 and 5). In the literature, 'self-harm' and 'deliberate self-harm' have been described either in absence of suicidal intent ${ }^{3} 1617$ or regardless of suicidal intent. ${ }^{18} 19$ The term 'deliberate self-harm' was not favoured in respondents' answers; their comments suggested that it could be stigmatising. The term 'self-harm' could thus be defined as a non-fatal act in which a person harms himself or herself, and intent to die is either absent or not accessible to observation. The question remains as to whether this term could be placed in an overarching position in a nomenclature, regardless of the level of intent to die (thus including 'suicide attempt'). Statement of intent differs depending on the person interviewed (eg, patient, family or clinician) and timing of the interview (eg, intent to die could be masked or denied when the patient becomes aware of the possibility of being admitted to a locked inpatient unit). For example, Kapur et $a l^{20}$ argued against distinguishing acts of self-harm according to intent.

Based on the current results, if intent to die has been stated by the patient, it may be more appropriate to consider the term 'suicide attempt' rather than 'self-harm', even if it seems to contradict the definition of suicide resulting from this survey. One might imagine another term for fatal suicidal behaviour in which evidence is not clear (eg, 'fatal self-harm'); however, respondents did not suggest a term for this specific situation.

Regarding 'suicidal ideation', Silverman and De Leo ${ }^{7}$ distinguished between 'no ideation' versus 'undetermined degree' versus 'some suicidal intent', and further subdivided the categories into 'casual', 'transient', 'passive', 'active' and 'persistent'. The responses to our survey suggest a rather inclusive definition of 'suicidal ideation': Thinking of suicide with or without suicidal intent; hoping for death by killing oneself; and, stating the presence of suicidal intention without engaging in behaviour. Further research may consider subdividers such as with/without suicidal intent, transient, reactive, persistent or with communication.
'Death wishes' were defined by respondents as hoping for death without thoughts of killing oneself, and were less inclusive than Balaguer et $a l \mathrm{~s}^{21}$ 'wish to hasten death', which was an overarching category including suicidal ideation.

O'Carroll et $a l^{2}$ defined 'suicide threat' as any interpersonal action, verbal or nonverbal, stopping short of a directly self-harmful act that a reasonable person would interpret as communicating or suggesting that a suicidal act or other suicide-related behaviour might occur in the near future (p247). Silverman $e t a l^{7}$ defined this term in a similar way. Vignette 12 was a case scenario designed to illustrate this definition. However, many participants did not respond to this vignette, and the significant disagreement between groups should lead to caution in interpreting results.

Based on responses to our survey, a 'suicide plan' could be defined as having decided how and when to perform a suicidal act. This definition is comparable to that of Silverman and De Leo, ${ }^{7}$ which does not include preparatory behaviour. A suggested definition should thus exclude active preparation.

Despite some disagreement between respondents, 'preparatory suicidal behaviour' could be defined as preparing for a suicidal act (eg, collecting pills, buying a gun, attaching a rope, visiting a bridge), but without initiating it and thus not sustaining any injury. This definition is similar to that given by Posner et al. ${ }^{22}$ However, these authors also considered 'aborted' and 'interrupted suicide attempt' and thus a preparatory act was an umbrella term, which was not the case for our survey. Based on results, an 'aborted suicide attempt' could be defined as an act in which a person initiates a suicidal act (eg, stands or sits on the edge of a high bridge; ties a rope around his or her neck; etc), but stops himself/herself before sustaining any injury (vignette 15).

An 'interrupted suicide attempt' could be defined as initiating a suicidal act (eg, standing or sitting on the edge of a high bridge, tying a rope around one's neck), but being stopped by someone else before sustaining any injury (vignette 16). These definitions are indeed comparable to those reported by Posner $e t a l^{22}$

\section{Differences between HICs and LMICs}

Access to resources (eg, local research activity) could have an influence on terminology. Therefore, it was expected that the level of national income has an influence on preferred terminology of the respondents, considering the fact that HICs have more resources for professionals working in suicidology, advanced healthcare systems and more academic and research background than LMICs. Furthermore, there are notable historical and cultural differences (eg, religious), which could have further impact on the terminology. Nevertheless, lack of previous empirical studies did not enable us to propose a clear testable hypothesis.

However, our results identified some notable differences between respondents from LMICs and HICs. Respondents from HICs were more likely to agree that, in suicide, intent may be ambiguous or unclear. Differences in responses to vignette 4 (ie, non-fatal suicidal behaviour, 
but person cannot state intentions) could suggest that respondents from LMICs did not distinguish non-fatal behaviours as precisely regarding intent as respondents from HICs, who were more likely to name the behaviour 'self-harm'. Interestingly in vignette 6 (ie, fatal suicidal behaviour with no evidence of intent), respondents from HICs were more likely to choose 'undetermined death' rather than 'suicide', which was somewhat in contradiction with an open definition of suicide regarding intent. Some differences were found for vignette 11, 12 and 14, but none of these related to a pattern in which respondents form HICs had more precise terminology than respondents from LMICs. Overall, no clear differential pattern could be evidenced in responses given for the four characteristics of suicide, and respondents from LMICs had an equal range of terms to name the behaviours in the vignettes.

\section{Strengths and limitations}

Representatives of 63 countries (slightly less than a third of all 193 WHO member countries) participated in the ISDELTSB. If any nomenclature has to be internationally applicable, efforts should be dedicated to increasing the number of countries taking part in this type of research, especially among LMICs. It should be noted that seven out of 30 LMICs (23\%) had a national suicide prevention strategy, compared with 15 out of 33 HICs (45\%). Yet, despite their relatively low number, participating countries account for two thirds of the world population and three quarters of all suicides. ${ }^{23}$

LMICs were represented by 37 and HICs by 89 respondents, which implies a bias towards responses from HICs and the analysis showed a few notable differences. However, we conducted additional sensitivity analyses, which gave similar results. Nevertheless, the relatively high number of LMICs included in the study was achieved by using a recruitment approach based on institutionally and self-defined expertise. The fact that there was no operational definition regarding expertise in suicidology is another limitation to our study. However, differences between the HICs are also very likely.

The initial idea of using one 'representative' per country (the IASP national delegate) was chosen to give comparable weight to all participating countries. Poor response to initial recruitment efforts led to our extending participation to individual members of IASP. However, the final number of participants remained quite low; the obtained results thus need to be replicated in studies with bigger samples.

As mentioned in the companion paper on methodology, ${ }^{3}$ the questionnaire was not translated into different languages but presented in English. This has probably limited participation to the study; in addition, it may have led to discrepancies in understanding questions. We need to acknowledge that all conclusions should be taken with caution.

\section{Implications for further research}

Table 1 collates the most frequently chosen terms together, with their matching definition. The resulting nomenclature
Table 1 Recommended nomenclature of suicidal behaviours after the International Study of Definitions of English-Language Terms for Suicidal Behaviors

\begin{tabular}{|c|c|}
\hline $\begin{array}{l}\text { Designating } \\
\text { term or } \\
\text { expression }\end{array}$ & Definition \\
\hline Suicide & $\begin{array}{l}\text { An act resulting in death which is initiated and } \\
\text { carried out by an individual to the end of the } \\
\text { action, with the knowledge of a potentially } \\
\text { fatal result, and in which intent may be } \\
\text { ambiguous or unclear, may involve the risk of } \\
\text { dying, or may not involve explicit intent to die. }\end{array}$ \\
\hline $\begin{array}{l}\text { Suicide } \\
\text { attempt }\end{array}$ & $\begin{array}{l}\text { An act in which a person harms himself or } \\
\text { herself, with the intention to die, and survives. }\end{array}$ \\
\hline Self-harm & $\begin{array}{l}\text { A non-fatal act in which a person harms } \\
\text { himself or herself intentionally, with varying } \\
\text { motives including the wish to die. }\end{array}$ \\
\hline $\begin{array}{l}\text { Suicic } \\
\text { ideati }\end{array}$ & $\begin{array}{l}\text { To think of suicide with or without suicidal } \\
\text { intent, or hope for death by killing oneself, or } \\
\text { state suicidal intention without engaging in } \\
\text { behaviour. }\end{array}$ \\
\hline Death wishes & $\begin{array}{l}\text { To hope for death without thoughts of killing } \\
\text { oneself. }\end{array}$ \\
\hline Suicide plan & $\begin{array}{l}\text { To have decided how and when to perform a } \\
\text { suicidal act, but without active preparation. }\end{array}$ \\
\hline $\begin{array}{l}\text { Preparatory } \\
\text { suicidal } \\
\text { behaviour }\end{array}$ & $\begin{array}{l}\text { To prepare a suicidal act (eg, assemble pills, } \\
\text { buy a gun, attach a rope, visit a bridge), but } \\
\text { without initiating it and thus not sustaining } \\
\text { any injury. }\end{array}$ \\
\hline $\begin{array}{l}\text { Aborted } \\
\text { suicide } \\
\text { attempt }\end{array}$ & $\begin{array}{l}\text { An act in which a person initiates a suicidal } \\
\text { act (eg, stands or sits on the edge of a high } \\
\text { bridge, ties a rope around his or her neck), but } \\
\text { stops himself/herself before sustaining any } \\
\text { injury. }\end{array}$ \\
\hline $\begin{array}{l}\text { Interrupted } \\
\text { suicide } \\
\text { attempt }\end{array}$ & $\begin{array}{l}\text { An act in which a person initiates a suicidal } \\
\text { act (eg, stands or sits on the edge of a high } \\
\text { bridge, ties a rope around his or her neck), but } \\
\text { is stopped by someone else before sustaining } \\
\text { any injuries. }\end{array}$ \\
\hline
\end{tabular}

can be considered as an attempt at promoting consensus in a wide range of cultural settings. It tries to encompass the whole range of suicidal behaviours and ideation. However, as mentioned earlier, not everything comes as crystal clear. For example, suicide was frequently interpreted as an act performed to completion by the actor itself, not involving a third agent. Intent to die appears as necessary to define a suicide attempt, but intent can be vague or unclear for a suicide. There are terms that may receive an overarching character. For instance, 'self-harm' may include behaviours in which there is no intent to die and those in which intent is unknown.

The 'preparatory suicidal behaviour' category could include both 'aborted' and 'interrupted suicide attempt' or, as suggested in our survey, these may be treated as distinct, owing to differences in the moment in which the behaviour 
stops (ie, after preparations are finished or after the suicidal act is initiated).

The nomenclature presented in table 1 should thus be considered as a working base to advance in the direction of a universal classification of suicidal behaviours.

\section{CONCLUSION}

The development of an internationally applicable nomenclature and classification of suicidal behaviours would be a long and complex process. The IASP Special Interest Group on Nomenclature would be ideally positioned to carry out this task with the help of a large and motivated international membership. Using the results of an international opinion survey, a tentative nomenclature of suicidal behaviour is proposed. Indications from this survey may be used by the Special Interest Group. Future developments could then be tested in large samples of professionals (eg, clinicians, researchers), with particular attention to intercultural and interdisciplinary representativeness. One of the challenges of this process would be the involvement of LMICs, keeping in mind that online surveys like ours have only moderate success in representing LMICs. ${ }^{24}$

\section{Author affiliations}

${ }^{1}$ Australian Institute of Suicide Research and Prevention, School of Applied

Psychology, Griffith University, Mt Gravatt, Queensland, Australia

${ }^{2}$ Centre Hospitalier Albert Bousquet, Nouméa, New Caledonia

${ }^{3}$ Medical College of Wisconsin, Milwaukee, Wisconsin, USA

${ }^{4}$ Department of Psychiatry and Behavioral Sciences, Johns Hopkins School of Medicine, Baltimore, Maryland, USA

${ }^{5}$ Departments of Psychiatry and Radiology, Columbia University, New York City, New York, USA

${ }^{6}$ National Suicide Research Foundation, School of Public Health, University College Cork, Cork, Ireland

${ }^{7}$ Centre for Suicide Research, Oxford University, Oxford, UK

${ }^{8}$ Suicide Research and Prevention Center, Shanghai Mental Health Center, Shanghai Jiao Tong University School of Medicine, Shanghai, China

${ }^{9}$ Departments of Psychiatry and Epidemiology, Columbia University, New York City, New York, USA

${ }^{10}$ Department of Psychiatry, The Voluntary Health Services Hospital, Chennai, India

${ }^{11}$ Centre for Mental Health, Melbourne School of Population and Global Health, The

University of Melbourne, Melbourne, Victoria, Australia

${ }^{12}$ Department of Psychology, University of Guanajuato, Guanajuato, Mexico

${ }^{13}$ Department of Psychiatry, University of Western Ontario, London, Ontario, Canada

${ }^{14}$ Center for the Study and Prevention of Suicide, University of Rochester, Rochester, New York, USA

Acknowledgements For their assistance in recruiting participants and distributing the questionnaire we are extremely grateful to IASP Administrative Officers, Wendy Orchard and Wendy Cliff; Professor Roy Abraham Kallivayalil, Secretary General at the WPA, as well as the WPA team; Professor Chris Dowrick, Chair of Working Party for Mental Health at WONCA, as well as the WONCA team. We would also like to acknowledge all those who participated in ISDELTSB (): Dr Bashir Sarwari, Dr Ernesto Ruben Paez, Dr Jo Robinson, Dr Thomas Niederkrotenthaler, Dr Gwendolyn Portzky, Dr Daravuth Yel, Professor Jie Zhang, Dr Marta Ardilla, Dr Annette Erlangsen, Professor Merike Sisask, Dr Stephane Amadeo, Dr Reinhard Lindner, Professor Charity Akotia, Professor Christos Lionis, Dr Frances Yik Wa Law, Dr Sandor Fekete, Dr Wilhelm Nordfjord, Professor Seyed Kazem Malakouti, Dr Marco Innamorati, Dr Chiaki Kawanishi, Merab Mulindi, Professor Elie Karam, Dr Paulius Skruibis, Neeteeyavathee Appadoo, Dr Liuba Ceban, Dr Remco De Winter, Dr Sylvia Huitson, Dr Alexandre Teixeira, Dr Linnette Rodriguez Figueroa, Dr. Suhaila Ghuloum, Dana-Cristina Herta, Anna-Lisa Labiche, Dr Vita Postuvan, Andoni Ansean, Dr Gergo Hadlaczky, Assistant Professor Prakarn Thomyangkoon, Dr Puloka mapa haano, Professor Gerard Hutchinson, Dr James Mughisha, Professor Vsevolod Rozanov, Dr
Bianca Hedge, Professor Madelyn Gould, Dr Silvia Peláez, Dr Alan Apter, Professor Ad Kerkhof, Dr Siegrid Darquet, Professor José Manoel Bertolote, Dr Benedikt Till, Professor Michel Tousignant, Dr Tracy McCown, Dr M M Jalal Uddin, Professor Øivind Ekeberg, Bronwen Edwards, Dr Priya Sreedaran, Dr Mitsuhiko Yamada, Karen Lascelles, Professor Jean Pierre Soubrier, Angela Clapperton, Dr Tracey King, Dr Ann Luce, Professor Stephen Platt, Dr Daniel Reidenberg, Dean Martin, Eleanor Bailey, Barry Taylor, Ann Evans, Karen Scavacini, Gert Jessen, Diana Rucli, Dr. Chencho Dorji, Dr Saska Roskar, Dr John Draper, Dr Nathaniel Pollock, Dr Aggrey Burke, Dr Freddy Vasquez, Professor William Feigelman, Sean McCarthy, Luis Miguel Sánchez-Loyo, Andrew Humphreys, Dr Gabriela Silva de Malafaia, Christine Genest, Professor Chan Lai Fong, Professor Deborah Goebert, Veronica Rose Marshall Bernard, Lakshmi Ratnayeke, Ricardo Gusmão, Professor Chris G Caulkins, Jill Fisher, Professor Thomas Bronisch, Ernest Garnark Smith Jr., Dr Ellyson Stout, Professor Merete Nordentoft, Dr Zonda Tamás, Christine Wong, Rev. Cody Cooper, Dr Pandit Devjyoti Sharma, Sally Morris, Nicole Hill, Dr Kate Fairweather-Schmidt, Professor Ping Qin, Professor lan R.H. Rockett, Dr Maree Inder, Dr Gabrielle Jenkin, Dr Liv Mellesdal, Thomas Tarurongo Wynne, Lena Lenehan, Professor Yueqin Huang, Dr Derek de Beurs, Uzma Irfan, Rosina Acharya. We also thank all those participants who wished to remain anonymous.

Contributors DDL originated the study idea and design, designed and critically reviewed the questionnaire, interpreted data and drafted the manuscript. BG helped design the study, designed the questionnaire, analysed and interpreted data and drafted the manuscript. MS, AB, JM, EA, KH, MRP and LV contributed to the methodology, reviewed the questionnaire, interpretation of data and critically reviewed the manuscript. KA, A-MC-H and MH contributed to the interpretation of data and critically reviewed the manuscript. KK helped design the study, helped design and critically reviewed the questionnaire, analysed and interpreted data and critically reviewed the manuscript.

Funding The authors have not declared a specific grant for this research from any funding agency in the public, commercial or not-for-profit sectors.

Map disclaimer The depiction of boundaries on this map does not imply the expression of any opinion whatsoever on the part of $B M J$ (or any member of its group) concerning the legal status of any country, territory, jurisdiction or area or of its authorities. This map is provided without any warranty of any kind, either express or implied.

Competing interests None declared.

Patient consent for publication Not required.

Ethics approval All procedures were approved by the Griffith University's Human Research Ethics Committee (2017/601).

Provenance and peer review Not commissioned; externally peer reviewed.

Data availability statement Data are available upon reasonable request. Data can be made available upon a reasonable request.

Supplemental material This content has been supplied by the author(s). It has not been vetted by BMJ Publishing Group Limited (BMJ) and may not have been peer-reviewed. Any opinions or recommendations discussed are solely those of the author(s) and are not endorsed by BMJ. BMJ disclaims all liability and responsibility arising from any reliance placed on the content. Where the content includes any translated material, BMJ does not warrant the accuracy and reliability of the translations (including but not limited to local regulations, clinical guidelines, terminology, drug names and drug dosages), and is not responsible for any error and/or omissions arising from translation and adaptation or otherwise.

Open access This is an open access article distributed in accordance with the Creative Commons Attribution Non Commercial (CC BY-NC 4.0) license, which permits others to distribute, remix, adapt, build upon this work non-commercially, and license their derivative works on different terms, provided the original work is properly cited, appropriate credit is given, any changes made indicated, and the use is non-commercial. See: http://creativecommons.org/licenses/by-nc/4.0/.

\section{ORCID iDs}

Benjamin Goodfellow http://orcid.org/0000-0003-0554-3701

Keith Hawton http://orcid.org/0000-0003-4985-5715

Karl Andriessen http://orcid.org/0000-0002-3107-1114

Kairi Kolves http://orcid.org/0000-0002-1638-8981

\section{REFERENCES}

1 Beck AT, Davis JH, Frederick CJ, et al. Classification and nomenclature. In: Resnik HLP, Hathorne BC, eds. Suicide prevention 
in the 70's. Center for Studies of Suicide Prevention, National Institute of Mental Health, 1973: 7-12.

2 O'Carroll PW, Berman AL, Maris RW, et al. Beyond the tower of babel: a nomenclature for suicidology. Suicide Life Threat Behav 1996;26:237-52.

3 Silverman MM, Berman AL, Sanddal ND, et al. Rebuilding the tower of Babel: a revised nomenclature for the study of suicide and suicida behaviors. Part 2: suicide-related ideations, communications, and behaviors. Suicide Life Threat Behav 2007;37:264-77.

4 Goodfellow B, Kõlves K, de Leo D. Contemporary nomenclatures of suicidal behaviors: a systematic literature review. Suicide Life Threat Behav 2018;48:353-66.

5 Goodfellow B, Kõlves K, De Leo D. Contemporary classifications of suicidal behavior: a systematic literature review. Crisis 2020;41:179-86.

6 World Health Organization. International classification of diseases (ICD), 2016. Available: http://www.who.int/classifications/icd/en/ [Accessed 26 May 2020].

7 Silverman MM, De Leo D. Why there is a need for an international Nomenclature and classification system for suicide. Crisis 2016;37:83-7.

8 World Health Organization. National suicide prevention strategies: progress, examples and indicators, 2018. Available: https://www. who.int/mental_health/suicide-prevention/national_strategies_2019/ en/ [Accessed 21 Apr 2020].

9 Goodfellow B, Kõlves K, de Leo D. Contemporary definitions of suicidal behavior: a systematic literature review. Suicide Life Threat Behav 2019;49:488-504.

10 Goodfellow B, Kõlves K, De Leo D, et al. International study of definitions and terms for suicidal behaviors (0): protocol of an opinion survey. BMJ Open 2019;2019:e025770.

11 Baechler J. A strategic theory. Suicide Life Threat Behav 1980;10:70-99.

12 Egel L. On the need for a new term for suicide. Suicide Life Threat Behav 1999;29:393-4.
13 De Leo D, Burgis S, Bertolote JM, et al. Definitions of suicidal behavior: lessons learned from the WHO/EURO multicentre study. Crisis 2006;27:4-15.

14 Stengel E. The suicidal attempt as a behaviour pattern, and its definition. In: Stengel E, ed. Suicide and attempted suicide. London: Penguin Books, 1964: 67-73.

15 Padmanathan P, Biddle L, Hall K, et al. Language use and suicide: an online cross-sectional survey. PLoS One 2019;14:e0217473.

16 Mangnall J, Yurkovich E. A literature review of deliberate self-harm. Perspect Psychiatr Care 2008;44:175-84.

17 Marusic A. Toward a new definition of suicidality? Are we prone to Fregoli's illusion? Crisis 2004;25:145-6.

18 Dear G. Further comments on the nomenclature for suicide-related thoughts and behavior. Suicide Life Threat Behav 2001;31:234-5.

19 Hawton K, Harriss L, Hall S, et al. Deliberate self-harm in Oxford, 1990-2000: a time of change in patient characteristics. Psychol Med 2003;33:987-95.

20 Kapur N, Cooper J, O'Connor RC, et al. Non-suicidal self-injury $\mathrm{V}$. attempted suicide: new diagnosis or false dichotomy? $\mathrm{Br} \mathrm{J}$ Psychiatry 2013;202:326-8.

21 Balaguer A, Monforte-Royo C, Porta-Sales J, et al. An international consensus definition of the wish to hasten death and its related factors. PLoS One 2016;11:e0146184.

22 Posner K, Oquendo MA, Gould M, et al. Columbia classification algorithm of suicide assessment (C-CASA): classification of suicidal events in the FDA's pediatric suicidal risk analysis of antidepressants. Am J Psychiatry 2007;164:1035-43.

23 World Health Organization. Suicide data, 2016. Available: https:// www.who.int/mental_health/prevention/suicide/suicideprevent/en/ [Accessed 26 May 2020].

24 Reed GM, Mendonça Correia J, Esparza P, et al. The WPA-WHO global survey of psychiatrists' attitudes towards mental disorders classification. World Psychiatry 2011;10:118-31. 